\title{
RENDIMIENTO DIAGNÓSTICO DEL WESTERN BLOT PARA DETECTAR SIMULTANEAMENTE ANTICUERPOS EN PACIENTES CON CISTICERCOSIS, HIDATIDOSIS Y FASCIOLIASIS HUMANA
}

\author{
Kelly Davelois $2, a$, Hermes Escalante ${ }^{2, b}$, César Jara ${ }^{1, c}$
}

\begin{abstract}
RESUMEN
Objetivo. Determinar el rendimiento diagnóstico de la técnica de Western Blot para detectar simultáneamente anticuerpos en pacientes con cisticercosis, hidatidosis y fascioliasis humana. Materiales y métodos. Estudio transversal de evaluación de prueba diagnóstica. Se obtuvieron los antígenos de excreción-secreción de las larvas de Taenia solium, quistes de Echinococcus granulosus; y la forma adulta de Fasciola hepática; que luego fueron separados electroforéticamente en geles de poliacrilamida individuales, transferidos y fijados a una membrana de nitrocelulosa para ser enfrentados con sueros de pacientes con las tres parasitosis. La sensibilidad de la técnica se evaluó empleando 300 sueros individuales, 60 pools de dos parasitosis y 20 pools de tres parasitosis y la especificidad con 75 sueros de pacientes con otras parasitosis, 10 de pacientes con otras enfermedades y 15 sueros de personas no parasitadas. Resultados. La técnica reconoció trece glicoproteínas (GP): GP 35, 31, 24, 23, 18, 17, 14 y 13 kDa para cisticercosis, GP 8,16 y 21 kDa para hidatidosis y GP: 17 y $23 \mathrm{kDa}$ para fascioliasis. La prueba detectó la presencia de anticuerpos alcanzando una sensibilidad de 96\% (IC95\%: 94,62-98,54\%) en la detección de una o las trece bandas, una especificidad de $100 \%$ (IC95\%: 99,50 - 100,00\%); individualmente, se tuvo una sensibilidad para cisticercosis de 97\% (IC95\%: 93,16-100\%), para hidatidosis de 94\% (IC95\%: 88,85-99,15\%) y para fascioliasis de 96\% (IC95\%: 91,66-100\%). Conclusiones. La prueba de Western blot es eficaz en la detección, simultanea de anticuerpos en pacientes con cisticercosis, hidatidosis y fascioliasis humana, y puede ser utilizada como prueba de descarte o confirmatoria en zonas endémicas.
\end{abstract}

Palabras clave: Cisticercosis; Equinococosis; Fascioliasis; Western blotting (fuente: DeCS BIREME).

\section{WESTERN BLOT DIAGNOSTIC YIELD FOR SIMULTANEOUS ANTIBODY- DETECTION IN PATIENTS WITH HUMAN CYSTICERCOSIS, HYDATIDOSIS, AND HUMAN FASCIOLIASIS}

\begin{abstract}
Objectives. To determine the diagnostic yield using western blotting to simultaneously detect antibodies in patients with human cysticercosis, hydatidosis, and human fascioliasis. Materials and methods. Cross-sectional study of diagnostic yield assessment. Excretory/secretory antigens were obtained from Taenia solium larvae, Echinococcus granulosus cysts, and the adult flukes of Fasciola hepática, which were then separated using the polyacrylamide gel electrophoresis technique, transferred, and attached to a nitrocellulose membrane to be probed with sera from the patient infected with the three parasites. The sensitivity of the technique was assessed using 300 individual serum samples, 60 pools of two parasites, and 20 pools of three parasites with 75 sera from patients with other parasites, 10 from patients with other diseases, and 15 from patients without parasites. Results. The technique revealed 13 glycoproteins (GP): GP 35, 31, 24, $23,18,17,14$, and $13 \mathrm{kDa}$ for cysticercosis; GP 8, 16, and $21 \mathrm{kDa}$ for hydatidosis; and GP 17 and $23 \mathrm{kDa}$ for fascioliasis. The test detected the presence of antibodies with a sensitivity of $96 \%(95 \%$ confidence interval $[\mathrm{Cl}]=94.62-98.54 \%)$ in the detection of one or the thirteen bands, a specificity of $100 \%(95 \% \mathrm{Cl}=99.50-100.00 \%)$; individually, there was a sensitivity for cysticercosis of $97 \%(95 \% \mathrm{Cl}=93.16-100.00 \%)$, for hydatidosis of $94 \%(95 \% \mathrm{Cl}=88.85-99.15 \%)$ and for fascioliasis of $96 \%(95 \% \mathrm{Cl}=91.66-100.00 \%)$. Conclusions. Western blotting is effective in the simultaneous detection of antibodies in patients with human cysticercosis, hydatidosis, and fascioliasis, and it can be used as a diagnostic test to either rule out or confirm the presence of antibodies in endemic areas.
\end{abstract}

Keywords: Cysticercosis, Ecchinococcosis; Fascioliasis; Blotting, western (source: MeSH NLM).

\footnotetext{
Facultad de Ciencias Biológicas, Universidad Nacional de Trujillo, La Libertad, Perú.

Laboratorio de Investigación y Desarrollo, ESCACORP S.A.C., La Libertad, Perú.

Biólogo microbiólogo; ${ }^{\mathrm{b}}$ magister en Parasitología; ${ }^{\mathrm{c}}$ doctor en Ciencias Biológicas.

Recibido: 25/04/2016 Aprobado: 12/10/2016
}

Citar como: Davelois K, Escalante H, Jara C. Rendimiento diagnóstico del Western Blot para detectar simultáneamente anticuerpos en pacientes con cisticercosis, hidatidosis y fascioliasis humana. Rev Peru Med Exp Salud Publica. 2016;33(4):616-24. doi: 10.17843/rpmesp.2016.334.2543 


\section{INTRODUCCIÓN}

La cisticercosis, hidatidosis y fascioliasis humana son zoonosis parasitarias consideradas por la Organización Mundial de Salud como enfermedades desatendidas. A nivel mundial, se estima que la cisticercosis afecta a 50 millones de personas y causa unas 50000 muertes anuales (4); por su parte, la hidatidosis puede presentar prevalencias de entre 5 y $10 \%$ y una tasa de incidencia de 50 por 100000 personas-año ${ }^{(5)}$. La fascioliasis humana es reportada en 51 países, con estimaciones entre 2,4 a 17 millones de personas afectadas mundialmente ${ }^{(6)}$.

La fascioliasis humana representa en el Perú un problema de salud pública, tiene una prevalencia global de $24,3 \%$ en el altiplano peruano, reportado en el 2002 mediante estudio coproparasitológico, y hasta un $71,4 \%$ con serología positiva para el $2004^{(7)}$; está presente en 18 de las 24 regiones del país, aunque se estima que existe una gran cantidad de casos subclínicos sin diagnosticar ${ }^{(8)}$. Las regiones con mayores prevalencias ${ }^{(9)}$ son Puno (Asillo) con $51,9 \%{ }^{(10)}$, Cajamarca entre 6,3 y $47,7 \%{ }^{(11)}$, Arequipa con $27 \%{ }^{(12)}$ Junín entre 0,9 a $11,7 \%^{(13)}$ y Cusco entre 9,7 y $10,3 \%{ }^{\prime(14)}$.

La prevalencia de la cisticercosis en el país, calculada a través de estudios serológicos -principalmente Western Blot-, va de 7,1 a $26,9 \%$ en áreas endémicas; la prevalencia de portadores de Taenia solium sería de hasta $6,7 \%$ en áreas endémicas, distribuidas en toda la sierra, costa norte y selva alta ${ }^{(15)}$; mientras, que la seroprevalencia de neurocisticercosis en estudios de población general fluctúa entre 23,4 y $35,87 \%{ }^{(16,17)}$.

El Perú es, probablemente, el país de las Américas con mayor prevalencia e incidencia de casos de hidatidosis; así, existen regiones cuyas prevalencias varían entre 14 y 34 por cada 100000 habitantes, como en Huancavelica, Ayacucho e Ica ${ }^{(19)}$. Se incrementa más la frecuencia en zonas endémicas en las que se puede encontrar prevalencias en humanos que van desde 5,5 a $9,1 \%$, y en ovejas y vacas de 77 y $68 \%$ respectivamente ${ }^{(18)}$.

En el Perú, se estima que la hidatidosis, la fascioliasis y la cisticercosis generarán muchos casos de hospitalizaciones, con aumento de personas en riesgo de infectarse -especialmente en niños- si no se cuenta con un buen sistema de control y vigilancia epidemiológica, por lo que se requiere técnicas de diagnóstico eficientes, rápidas, de fácil realización y de costo accesible ${ }^{(20)}$.

Actualmente, el diagnóstico de estas zoonosis se realiza por diversos métodos. Para la cisticercosis e hidatidosis se emplea el diagnóstico por imágenes y la serología por
ELISA y Western Blot, y para la fascioliasis se utilizan las técnicas coproparasitoscópicas, además de las dos pruebas serológicas mencionadas anteriormente.

El Western Blot es una técnica que permite reconocer anticuerpos por antígenos que se absorben en una membrana. Estos antígenos son previamente separados en geles de poliacrilamida-dodecil sulfato de sodio y luego transferidos a papel de nitrocelulosa. La unión antígeno-anticuerpo se detecta mediante la adición de un anticuerpo que reconoce la fracción constante de la inmunoglobulina humana, la cual está acoplada a una enzima. La unión se revela con la adición de un sustratocromogénico soluble el cual se precipita en el sitio en donde se encuentra el complejo antígeno-anticuerpo evidenciándose en forma de bandas coloreadas ${ }^{(21)}$.

La técnica de Western Blot ha mejorado el diagnóstico de diversas enfermedades y tiene ventaja sobre otras técnicas serológicas existentes en el mercado que no son asequibles en zonas endémicas por el costo elevado, el requerimiento de un equipo adicional, y por el proceso y el tiempo de realización ${ }^{(22)}$.

No obstante, la prueba de ELISA se sigue empleando como técnica de tamizaje, pero requiere confirmación por Western Blot en caso el resultado sea reactivo; paso adicional que demanda mayor tiempo y costo ${ }^{(22)}$. El uso de Western Blot está sustentado por su eficiencia para el diagnóstico de la cisticercosis con una sensibilidad de 91\%, determinada por Escalante, $98 \%$ por Tsang y $100 \%$ por Ayala ${ }^{(23)}$; para hidatidosis entre 75 y $80 \%{ }^{(24)}$ y para fascioliasis humana $95 \%{ }^{(25)}$; todos con una especificidad del $100 \%{ }^{(23-25)}$.

A nivel internacional no existe un producto comercial que permita evaluar de manera simultánea las parasitosis antes mencionadas a través de técnicas inmunológicas. Solo existen productos que utilizan técnicas de biología molecular, como el PCR multiplex, que permite detectar algunos parásitos intestinales ${ }^{(26)}$, el Semi-nested múltiple malaria PCR que permite el diagnóstico de cuatro tipos de Plasmodium ${ }^{(27)}$, entre otros; por lo tanto, consideramos necesario desarrollar una técnica inmunológica eficiente y rápida para el diagnóstico múltiple de cisticercosis, hidatidosis y fascioliasis humana, que permita mejorar el diagnóstico de estas zoonosis en zonas endémicas, disminuir costos y tiempos de procesos al utilizar un solo kit en lugar de tres.

En tal sentido, el presente estudio estuvo orientado a determinar el rendimiento diagnóstico de la técnica de Western Blot para la detección de anticuerpos individual y simultánea de la cisticercosis, la hidatidosis y la fascioliasis humana. 


\section{MATERIALES Y MÉTODOS}

\section{DISEÑO DEL ESTUDIO}

El diseño es transversal prospectivo de evaluación de pruebas diagnósticas.

\section{OBTENCIÓN DEL MATERIAL BIOLÓGICO}

La fuente de antígenos la constituyeron parásitos obtenidos de animales naturalmente parasitados, las larvas de Taenia solium (Cysticercus cellulosae) se obtuvieron de tres ejemplares de Sus scrofa domestica (cerdo) sacrificados en el matadero San Luis del distrito de La Esperanza, Trujillo, y el matadero único de la ciudad de Cajamarca; 67 larvas de Echinococcus granulosus (quiste hidatídico) de Ovis aries (ovino) de la Sociedad Agrícola de Interés Social "Tupac Amarú" del distrito de Pachacayo, Junín, y 245 formas adultas de Fasciola hepatica de Bos Taurus (vacuno) procedentes de las ciudades de Huamachuco y Cajamarca, sacrificados en el matadero El Porvenir de la ciudad de Trujillo.

\section{SELECCIÓN DE MUESTRAS}

Todas las muestras, seleccionadas por conveniencia, fueron proporcionadas por la Universidad Peruana Cayetano Heredia (UPCH), la Universidad Nacional de Cajamarca, el Hospital Referencial de Huancayo y el laboratorio clínico Escalabs.

Para evaluar la sensibilidad se usaron 300 sueros positivos: para cisticercosis (100), hidatidosis (100), y fascioliasis (100); además, 60 pools de sueros positivos para dos parasitosis y 20 pools positivos para tres parasitosis. Previamente, todas las enfermedades fueron confirmadas a través del diagnóstico por imágenes y Western Blot (cisticercosis y la hidatidosis) y por análisis coproparasitoscópicos y Western Blot (fascioliasis).

Para evaluar la especificidad de la técnica se usaron 100 sueros, de los cuales 75 fueron positivos a diferentes parasitosis: himenolepiasis (15), difilobotriasis (15), ascariasis (10), teniasis (15); trichuriasis (5), anquilostomiasis (10), y enterobiasis (5); todos confirmados por hallazgo de huevos en las heces; además, 10 sueros positivos usados para el estudio de enfermedades diferentes a las comprendidas en este estudio: 3 positivos a anticuerpos antinucleares, 3 a artritis reumatoidea, 2 a hepatitis, 2 a proteína $C$ reactiva y 15 sueros de personas no parasitadas, todas proporcionadas por el laboratorio clínico Escalabs y la $\mathrm{UPCH}$, cuya negatividad fue confirmada por examen coproparasitoscópico y por radiografía.

\section{PREPARACIÓN ANTIGÉNICA}

\section{ANTÍGENOS DE FASCIOLA HEPÁTICA}

Se obtuvieron los antígenos de excreción-secreción de Fasciola hepática mediante el cultivo in vitro en medio mínimo esencial de Eagle de formas adultas vivas, de ejemplares extraídos de los conductos biliares de varios hígados de bovino, como lo descrito por Escalante (25).

\section{ANTÍGENOS DE Ecchinococcus granulosus}

Se seleccionaron los hígados y pulmones de ovinos con sospecha de la presencia de quistes hidatídicos y luego fueron lavados con tampón fosfato salino (PBS) a $\mathrm{pH} 7,2$ estéril hasta que la superficie quede limpia y $\sin$ restos de tejidos o sangre. Con la ayuda de una jeringa estéril de $20 \mathrm{~mL}$, se perforó la pared de los quistes identificados y se extrajo todo el contenido líquido de su interior, que luego fue centrifugado a $4000 \mathrm{rpm}$ durante 5 min. El sobrenadante fue guardado en tubos estériles y el sedimento usado para buscar la arenilla hidatídica, la cual confirmó la presencia de un quiste hidatídico fértil. Luego, el líquido hidatídico separado en alícuotas de 1,5 $\mathrm{mL}$ fue centrifugado a $10000 \mathrm{rpm}$ durante $10 \mathrm{~min}$ a $4^{\circ} \mathrm{C}$.

\section{ANTÍGENOS DE LA LARVA DE Taenia solium}

Los antígenos de larva de Taenia solium fueron obtenidos de cisticercos identificados en los músculos y corazón de cerdos naturalmente infectados. Los cisticercos fueron colocados en un vaso de precipitado con PBS a pH 7,2, y luego lavados varias veces hasta que no se observe restos de tejidos. De cada uno de los cisticercos se extrajo, con la ayuda de una jeringa, el líquido vesicular, el cual fue centrifugado a $10000 \mathrm{rpm}$ por $10 \mathrm{~min}$ a $4^{\circ} \mathrm{C}$, en alícuotas de $1,5 \mathrm{~mL}$. La concentración de proteínas presentes en cada uno de los productos de excreciónsecreción de cada uno de los parásitos fue determinada por el método colorimétrico de Bradford

\section{ESTANDARIZACIÓN DE LA TÉCNICA DE WESTERN $B L O T$}

Para la estandarización se incluyeron todos los antígenos viables y los sueros positivos y negativos. Se excluyeron los sueros que poseían más de una parasitosis para la prueba de especificidad.

Los antígenos fueron evaluados individualmente para seleccionar el de mejor respuesta inmunológica, luego los antígenos seleccionados fueron evaluados a concentraciones de 0,$035 ; 0,05 ; 0,15$ y 0,2 ug/uL enfrentándolos con volúmenes de suero de $5,10,15$, 20,30 y 50 uL, con el conjugado a una concentración de $1 / 1000$, el peróxido de hidrógeno a volúmenes de $3,5,7$, 9 uL, la diaminobenzidina a 3, 5, 7 mg con volúmenes de 
proceso de 500 y 750 uL para estandarizar la técnica de Western Blot; además, se evaluó el orden de ubicación de los antígenos en la tira inmunorreactiva.

Con el fin de instrumentar esta técnica múltiple, se partió de la técnica de Western Blot descrito anteriormente ${ }^{(25)}$ con ciertas modificaciones de acuerdo a la estandarización de la técnica para el diagnóstico de la cisticercosis, hidatidosis y fascioliasis en forma individual; sin embargo, la técnica estandarizada sigue los siguientes pasos:

\section{PREPARACION ANTIGÉNICA}

Los antígenos obtenidos fueron tratados con $0,01 \mathrm{M}$ de Tris- $\mathrm{HCl} \mathrm{pH} \mathrm{8,0;1 \%} \mathrm{de} \mathrm{dodecil} \mathrm{sulfato} \mathrm{de} \mathrm{sodio,} 6 \%$ de glicerol y $1 \%$ de azul de bromofenol y $2,5 \mathrm{M}$ dithiothreitol, para luego ser calentado a $65^{\circ} \mathrm{C}$ por $20 \mathrm{~min}$.

\section{ELECTROFORESIS EN GEL DE POLIACRILAMIDA}

En la electroforesis se corrieron los antígenos preparados de cada parásito en geles individuales, los cuales fueron colocados en los pocillos en una cantidad equivalente a $1 \mathrm{uL}$ por $\mathrm{mm}$ de ancho de gel. Los corridos fueron hechos en minigeles de poliacrilamida de $8,3 \times 7 \times 0,075$ $\mathrm{cm}$ a la concentración de $15 \%$ en el gel resolución y $3 \%$ en el gel concentrador, utilizando marcador de peso molecular en el Mini PROTEAN $®$ Tetra Cell (Bio Rad Laboratories) y corridos a $200 \mathrm{~V}$ por $50 \mathrm{~min}$, de 2 a $8^{\circ} \mathrm{C}$.

\section{TRANSFERENCIA DE LAS PROTEINAS}

La transferencia de las proteínas de los tres parásitos contenidas en los geles a la membrana de nitrocelulosa de 0,2 um se hizo colocando primero el gel con los antígenos de C. cellulosae; luego, el gel con los antígenos de E. granulosus y finalmente de F. hepática, previa selección de los antígenos específicos y usando un buffer de transferencia $(0,2 \mathrm{M}$ de Tris- $\mathrm{HCl}, 20 \%$ de metanol y agua ultra pura) en el Trans Blot transfer Cell y se realizó a $100 \mathrm{~V}, 2$ A por $90 \mathrm{~min}$. La membrana fue cortada en tiras de $3 \mathrm{~mm}$ de ancho para ser evaluadas en placas de incubación de ocho canales.

\section{REACCION INMUNOENZIMÁTICA O ELISA}

Cada uno de los sueros fue preparado a la dilución de $1 / 33$ para los sueros controles y $1 / 17$ los sueros problema en PBS-Tween 20 y leche descremada en polvo a la dilución de $1 / 20$; siendo incubados con las tiras que contienen los antígenos de los tres parásitos ya fijados en agitación constante a temperatura ambiente por una hora. Después de ser lavadas con PBS-Tween 20 se colocaron en solución de conjugado enzimático (anti IgG humana marcada con Peroxidasa; Bio Rad Laboratories,
USA) a la dilución de 1/1000 por una hora; luego de 5 lavados, el revelado de los antígenos se realizó con un sustrato $\left(\mathrm{H}_{2} \mathrm{O}_{2}\right.$ al $0,01 \%$ y diaminobenzidina a $0,5 \mathrm{mg} /$ $\mathrm{mL}$ ) por espacio de $10 \mathrm{~min}$, deteniendo la reacción con agua ultra pura por $5 \mathrm{~min}$.

Bajo este procedimiento se seleccionó los tres mejores antígenos de cada parásito y se corrieron individualmente para luego ser unidos en la membrana y cortados en tiras, luego se elaboraron varios lotes, los cuales se usaron para determinar la concentración optima de suero, conjugado, sustrato, volúmenes de reactivo y tiempos de proceso; estandarizada la técnica se procedió con las pruebas de rendimiento diagnóstico.

\section{ANÁLISIS ESTADÍSTICO}

Se elaboró una tabla de contingencia de dos por dos para el cálculo de la sensibilidad, especificidad, valores predictivos, razones de verosimilitud (LR), índice de validez, prevalencia, e índice de Youden, considerando un nivel de confianza de $95 \%$. Se estimó la sensibilidad de la prueba en base a infecciones producidas por uno, dos y tres parásitos; primero se evaluó individualmente las tres parasitosis con el Western Blot para diagnóstico individual y luego con la prueba múltiple. El análisis estadístico se realizó utilizando el programa Epidat v3.1

\section{ASPECTOS ÉTICOS}

Los sueros utilizados en esta investigación fueron obtenidos previo consentimiento informado y procesados en condiciones de anonimización. Los protocolos empleados por todas las instituciones que proveyeron las muestras fueron aprobados por el Comité de Ética de la UPCH.

\section{RESULTADOS}

Un total de 488 muestras fueron consideradas para el estudio durante el periodo de agosto de 2014 y agosto de 2015. Las edades de los pacientes con cisticercosis estuvieron entre los 21 y 67 años, para hidatidosis entre 15 y 99 años, para fascioliasis entre 7 a 44 años, pacientes con otras parasitosis entre 20 a 61 años, patología diferente a la comprendida en el estudio de 38 a 55 años y de personas no parasitadas entre 20 y 45 años.

Del total de muestras, se excluyeron siete por contener muy poco volumen; luego, en la evaluación, se excluyó a una por presentar otra parasitosis adicional a la establecida. La muestra positiva a teniasis reaccionó para cisticercosis al momento del procesamiento; al realizar la evaluación con la técnica individual se confirmó la reacción determinándose ser positiva al complejo teniasis-cisticercosis (Figura 1). 


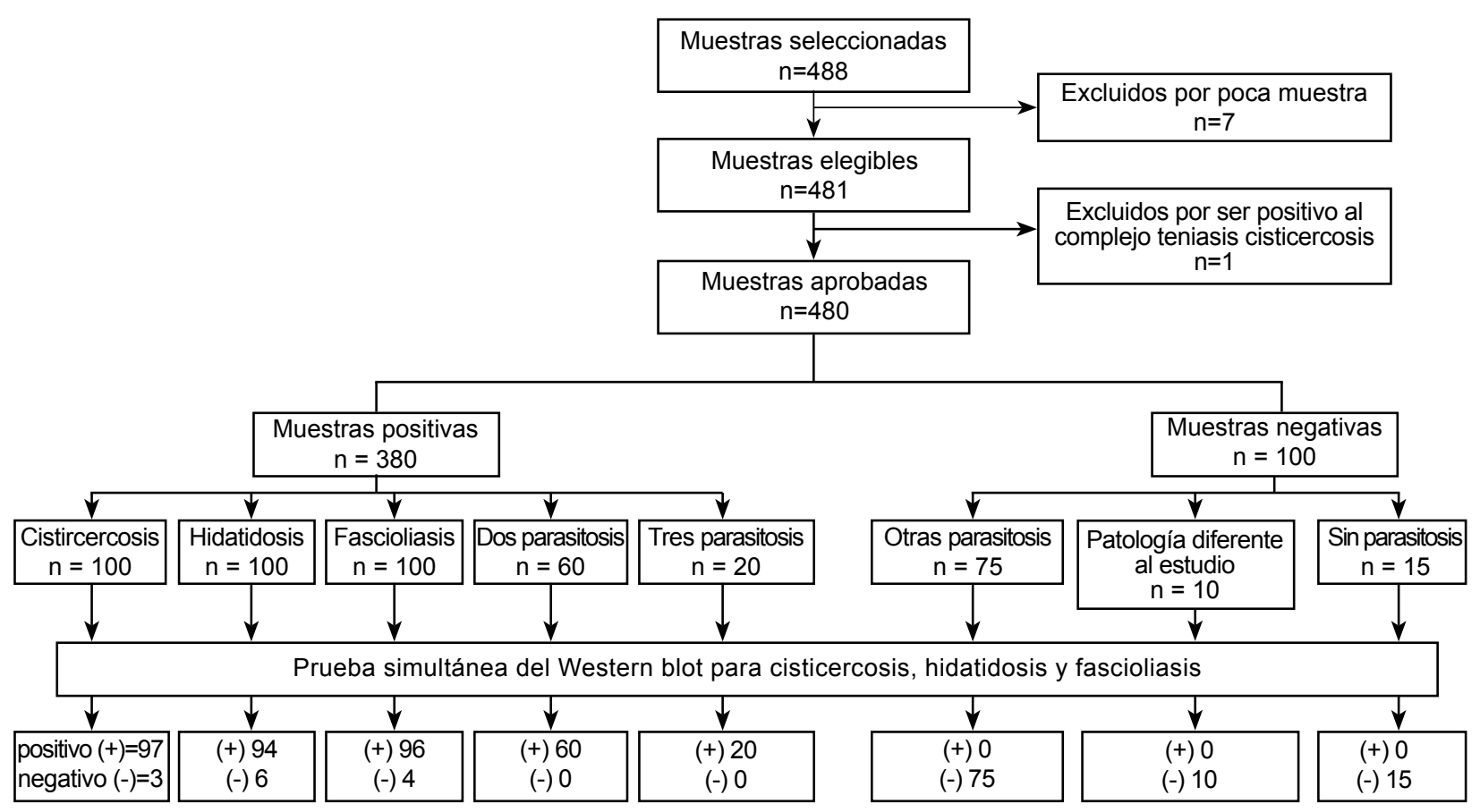

Figura 1. Diagrama de flujo de muestras incorporadas al estudio.

Se logró el desarrollo de una prueba múltiple que permite el diagnóstico serológico simultáneo de la cisticercosis, hidatidosis y fascioliasis humana mediante la técnica de Western Blot, capaz de detectar anticuerpos tipo IgG en sueros de pacientes infectados por la larva de $T$. solium (cisticercosis), la larva de E. granulosus (hidatidosis) y la forma adulta de $F$. hepatica (fascioliasis) en forma individual o simultánea (Figura 2).

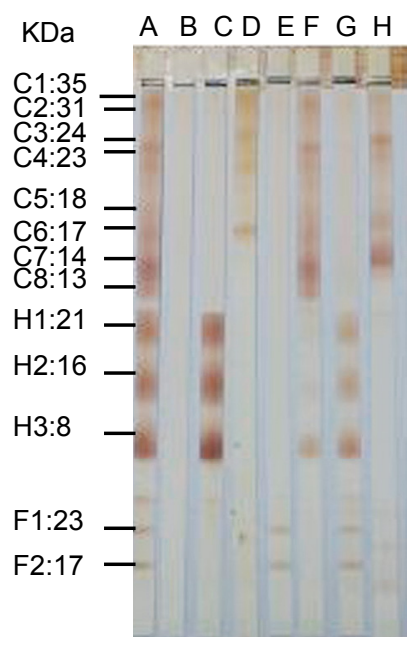

Figura 2. Patrón de reactividad de la prueba de Western Blot para detección de anticuerpos en suero. (A) positivo para cisticercosis, hidatidosis y fascioliasis; (B) control sin parasitosis; (C) positivo para hidatidosis; (D) positivo para cisticercosis; (E) positivo para fascioliasis; (F) positivo para cisticercosis e hidatidosis; (G) positivo para hidatidosis y fascioliasis; $(\mathrm{H})$ positivo para cisticercosis y fascioliasis.
Se determinó que las concentraciones óptimas de los antígenos que deben ser usadas en el desarrollo de la prueba son de 0,035 ug/uL para cisticercosis, y de $0,2 \mathrm{ug} / \mathrm{uL}$ para hidatidosis y fascioliasis. El volumen del suero control fue de $15 \mathrm{uL}$, y del suero problema $30 \mathrm{uL}$, la dilución de conjugado $1 / 1000$, el volumen de trabajo de 500 uL y tiempos de incubación de una hora.

El pool de sueros positivos a la tres parasitosis permitió reconocer 13 antígenos de excreción/secreción, ocho de C. cellulosae glicoproteínas para cisticercosis (GPC: $35,31,24,23,18,17,14,13)$; tres de E. granulosus $(\mathrm{GPH}$ : $21,16,8)$, y dos de F. hepática (GPF:23 y 17 KDa).

Se evaluó la sensibilidad con los 100 sueros positivos de cada una de las tres parasitosis estudiadas con el kit de Western Blot individual. Así, se obtuvo una sensibilidad del 97\% para cisticercosis (IC95\%: 93,16100\%), 94\% para hidatidosis (IC95\%: 88,85-99,15\%), y 96\% para fascioliasis (IC95\%: 91,66-100\%). Luego de evaluar los mismos sueros con la técnica de Western Blot para el diagnóstico serológico simultáneo, se logró similar respuesta inmunológica.

De los 380 sueros positivos, 287 de los 300 sueros positivos a una sola infección presentaron una reacción serológica positiva; todos los sueros de dos parasitosis (60) y de tres parasitosis (20) dieron reacción positiva (Figura 3).

De los 75 sueros de pacientes confirmados con otras parasitosis (Figura. 4), 10 de pacientes con 
A

B

C

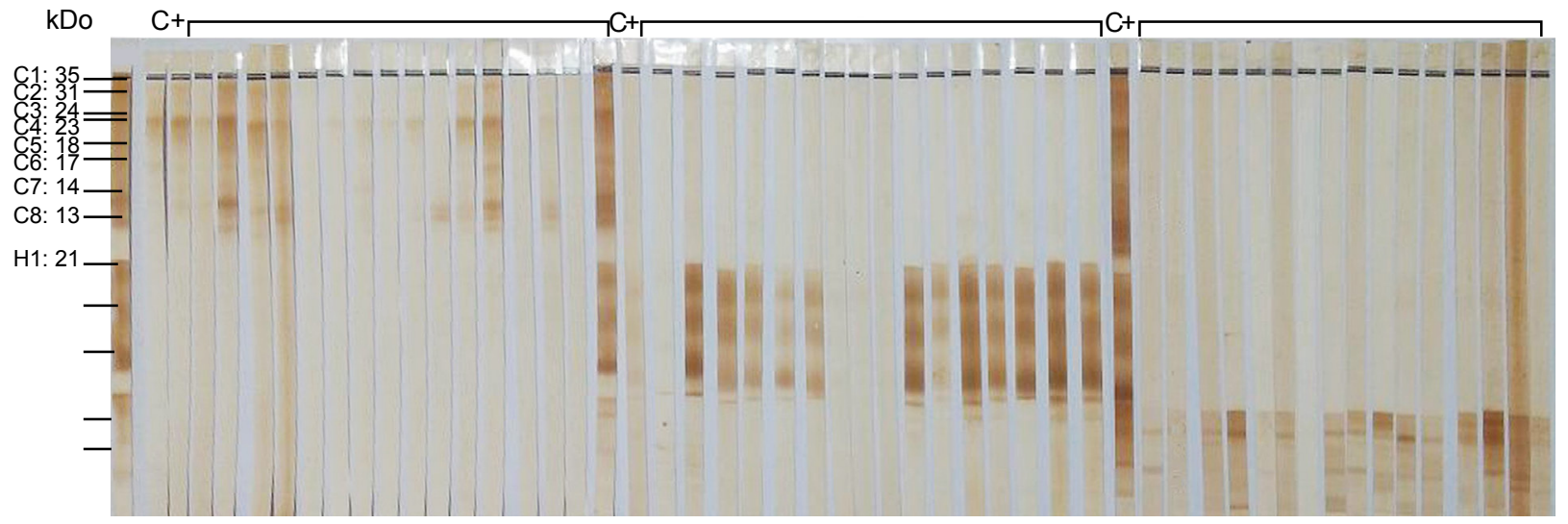

Figura 3. Patrón de reactividad de la prueba de Western Blot para detección de anticuerpos en suero. (C+) control positivo, positivo para $(A)$ cisticercosis, $(B)$ hidatidosis y $(C)$ fascioliasis.

enfermedades infecciosas y 15 de personas no parasitadas (Figura 5) que fueron utilizados para evaluar la especificidad, ninguno reconoció las bandas específicas.

El cálculo de la sensibilidad y la especificidad de la prueba se basó en la detección de una o las trece bandas antigénicas específicas, obteniéndose una sensibilidad de 96,58\% (IC95\%: 94,62-98,54\%), una especificidad del 100\% (IC95\%: 99,50-100\%). El valor predictivo positivo encontrado fue de 100\% (IC95\%: 99,86-100\%), valor predictivo negativo 88,50\% (IC95\%: $82,17-94,82 \%$ ), y razón de verosimilitud negativa (LR-) de 0,03 (IC95\%: 0,02-0,06), índice de validez 97,29\%, prevalencia $79,17 \%$ e índice de Youden 0,97 (Tabla 01).

La interpretación de los resultados se realizó tomando como criterios de reactividad para una muestra positiva cuando se observa coloración en una o más de las trece bandas específicas y un resultado negativo si no se observa coloración en ninguna de las bandas.

Tabla 1. Características de la prueba Western Blot para la detección simultanea de anticuerpos de cisticercosis, hidatidosis y fascioliasis humana

\begin{tabular}{lr}
\hline & \multicolumn{1}{c}{ Valor (IC 95\%) } \\
\hline Sensibilidad (\%) & $96,58(94,62-98,54)$ \\
Especificidad (\%) & $100,00(99,50-100,00)$ \\
\hline Índice de validez (\%) & $97,29(95,74-98,85)$ \\
Valor predictivo positivo (\%) & $100,00(99,86-100,00)$ \\
Valor predictivo negativo (\%) & $88,50(82,17-94,82)$ \\
Prevalencia (\%) & \\
$\quad$ Índice de Youden & $0,97(0,95-0,98)$ \\
Razón de verosimilitud positiva & - \\
Razón de verosimilitud negativa & $0,03(0,02-0,06)$ \\
\hline
\end{tabular}

IC 95\%: intervalo de confianza al $95 \%$

\section{DISCUSIÓN}

Debido a que el diagnóstico de varias parasitosis, incluso las intestinales, puede resultar desalentador mediante pruebas habituales en muestras fecales, se recomienda realizar pruebas indirectas ${ }^{(28,29)}$. Sin embargo, no todas estas pruebas son eficientes debido a problemas de sensibilidad o especificidad y su limitada accesibilidad en estudios de campo y laboratorios de zonas endémicas, ya sea por la complejidad de la técnica o el requerimiento de equipamiento. Este problema puede ser resuelto usando un kit basado en la técnica de Western Blot, pues a pesar de brindar resultados de naturaleza categórica o semicuantitativa, tiene la ventaja de ser capaz de detectar anticuerpos contra antígenos específicos; es accesible y de fácil interpretación, ya que no requiere de ningún instrumento para su lectura, pues se hace de forma visual (21); la simplicidad de la prueba -se dan resultados en un tiempo de cuatro horas-, sin equipamiento para su proceso con solo una placa de incubación y con la garantía de una eficiencia demostrada.

El diagnóstico de la cisticercosis, hidatidosis y fascioliasis por Western Blot empleando kits individuales tienen sensibilidades de $91^{(23)}, 80^{(24)}$ y $95 \%{ }^{(25)}$ respectivamente y una especificidad del $100 \%$, pero usar dos o tres kits en zonas endémicas de multiparasitismo dificulta el trabajo del analista, requiere mayor tiempo para el procesamiento y entrega de resultados, además de un mayor costo para el paciente. Este estudio demuestra que se puede elaborar un Western Blot múltiple para diagnosticar parasitosis con la misma eficiencia que los kits individuales.

Un punto importante es que cada antígeno parasitario fue corrido en un gel de poliacrilamida diferente, se seleccionaron solo los antígenos específicos, para luego unir los tres geles en una membrana de nitrocelulosa y 


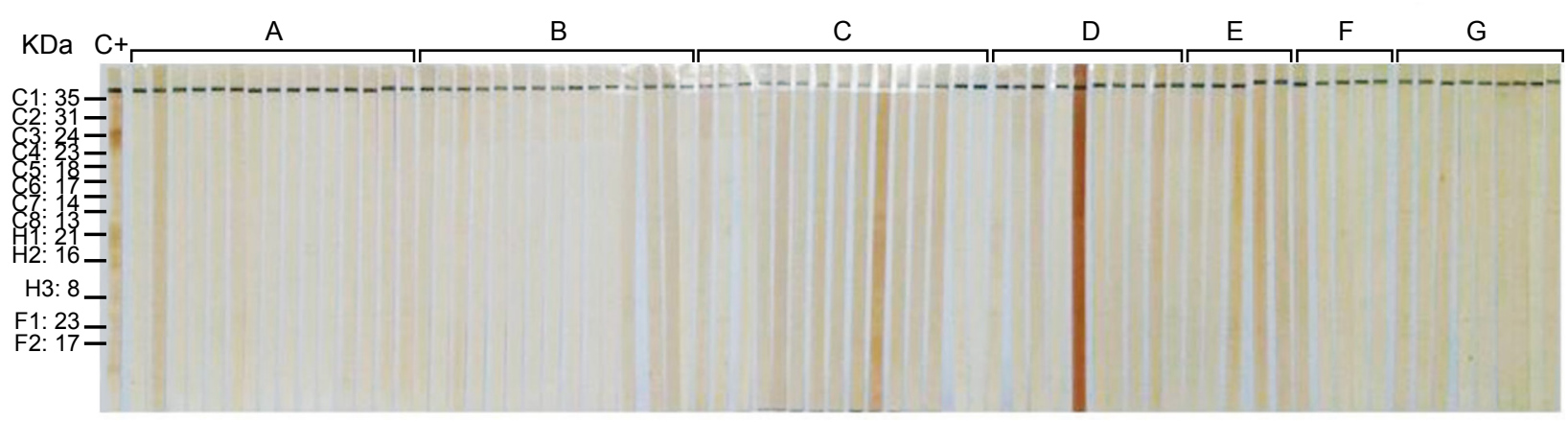

Figura 4. Patrón de reactividad de la prueba de Western Blot para detección de anticuerpos en sueros de individuos con otras enfermedades parasitarias: $(C+)$ control positivo, $(A)$ teniasis, $(B)$ himenolepiasis, $(C)$ difilobotriasis, $(D)$ ascariasis, $(E)$ trichuriasis, $(F)$ enterobiasis y $(G)$ anquilostomiasis.

así garantizar una buena reacción inmunológica y una alta especificidad, pues no se están sobreponiendo los antígenos ni se ha realizado un homogenizado que podría generar reacciones cruzadas.

Los resultados mostraron el mismo comportamiento inmunológico entre la técnica individual para el diagnóstico de cada parasitosis y la técnica para el diagnóstico simultáneo de las tres parasitosis, esto, debido a que se usaron los mismos antígenos, pero con diferentes concentraciones y volúmenes.

Para lograr una buena estandarización tuvimos en cuenta la naturaleza del antígeno, el tipo de antígeno, los ensayos de valoración de los anticuerpos producidos y la propiedad de la técnica para obtener la especificidad deseada. El desarrollo y aplicación de las pruebas serológicas se ve afectado por la dificultad para obtener cantidades suficientes de antígeno, mucha más si es de excreciónsecreción y con elevada pureza que permitan obtener una mayor sensibilidad y especificidad que garantice la homogeneidad y control de calidad del ensayo ${ }^{(30)}$.

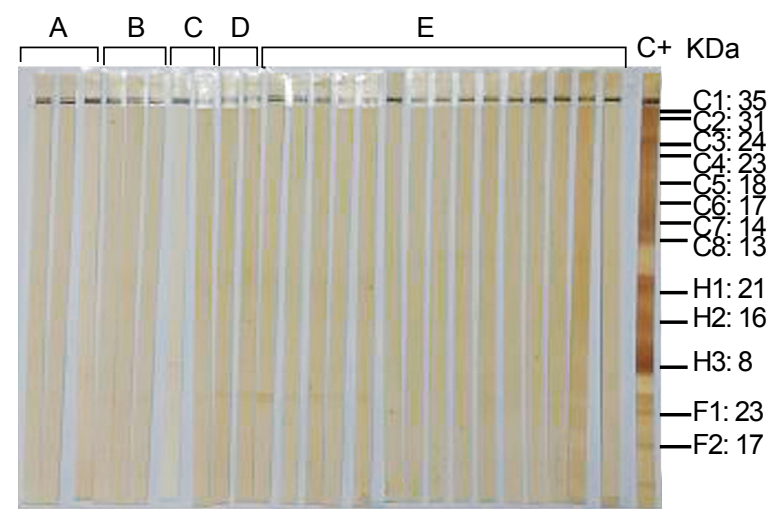

Figura 5. Patrón de reactividad de la prueba de Western Blot para detección de anticuerpos en suero de individuos que no tienen anticuerpos anticisticerosis, antihidatidosis y/o antifascioliasis. (A) anticuerpos antinucleares, (B) artritis reumatoide, $(C)$ hepatitis $B,(D)$ proteína $C$ reactiva, $(E)$ sin parasitismo y $(\mathrm{C}+)$ control positivo.
Los sueros positivos a cisticercosis determinados con anterioridad mediante historia clínica, imágenes y pruebas serológicas que dieron un resultado negativo en esta técnica, posiblemente se debió a que presenta una reacción a la banda $50 \mathrm{KDa}$ del antígeno purificado, la cual no se encuentra en nuestro antígeno, y a que presenta un título de anticuerpos muy bajo, por lo que no pudo ser detectado en el Western Blot; los sueros positivos a hidatidosis y los sueros positivos a fascioliasis determinados con anterioridad dieron un resultado negativo en esta técnica por presentar un título de anticuerpos muy bajo.

La principal ventaja que presenta la técnica es que se basa en la detección de antígenos de excreciónsecreción del parásito vivo, otorgándole la capacidad de diagnosticar la infección activa, además de eliminar las bandas inespecíficas para usar solo las específicas garantizando la eficiencia de la técnica

El contar con tres antígenos parasitarios en una sola tira inmunorreactiva, otorga a la técnica la capacidad de detectar anticuerpos contra $C$. cellulosae, E. granulosus y $F$. hepática, ya sea en pacientes que presentan una o múltiples parasitosis, permitiendo al analista reducir costos, simplificar los procesos y reducir los tiempos; y al paciente, reducir costos y tiempo en la entrega de sus resultados.

El rendimiento diagnóstico de la técnica de Western Blot simultáneo obtuvo una sensibilidad de $96 \%$ y especificidad de $100 \%$, lo cual es mayor a los kits individuales, esto permitirá continuar con las investigaciones para la producción del kit de diagnóstico simultáneo, donde toda la técnica esté simplificada al último paso que consistirá en el revelado enzimático en base a la técnica de ELISA indirecto cualitativo en cuatro horas.

Se concluye que la técnica de Western Blot desarrollada para el diagnóstico serológico individual y simultáneo de la cisticercosis, la hidatidosis y la fascioliasis humana puede ser de utilidad en estudios epidemiológicos o como técnica confirmatoria en zonas endémicas de multiparasitismo. 
Contribución de autoría: HE y DK participaron en la concepción y diseño del estudio, JC y DK en la recolección de datos, DK en el análisis e interpretación de datos, JC con asesoría técnica, HE y JC realizaron la revisión crítica de artículo. Todos los autores aprobaron la versión final del artículo y asumen la responsabilidad del contenido.

Fuente de financiamiento: Programa Innovate Perú (convenio 161 FIDECOM - FINCYT- PIPEI 2014).
Conflictos de Interés: los autores declaran no tener conflictos de interés.

Agradecimientos: A los biólogos Adderly Benites y Renzo Espinoza; al Dr. Pedro Ortiz (Universidad de Cajamarca) y al Dr. Hugo García (Universidad Peruana Cayetano Heredia) por proporcionarnos el material biológico. A Miguel Iglesias por su apoyo con el control de calidad y a los tesistas Sheyla Avalos y Omar Rosas en la estandarización de la técnica.

\section{REFERENCIAS BIBLIOGRÁFICAS}

1. Hotez PJ, Molyneux DH, Fenwick A, Kumaresan J, Ehrlich S, Sachs JD, et al. Control of neglected tropical diseases. N Engl J Med. 2007;357(10):1018-27. doi: 10.1056/NEJMra064142

2. Budke C, White A, Garcia H. Zoonotic larval cestode infections: neglected, neglected tropical diseases? Plos Negl Trop Dis. 2009;3(2): e319. doi: 10.1371/ journal.pntd.0000319

3. Kenyon S, Catalá L, Grados M, Gonzálvez G, Castellanos L. El camino a la eliminación: un panorama de las enfermedades infecciosas desatendidas en América Latina y El Caribe. Rev. Perú. Med. Exp. Salud pública.2014; 31(2):319-25.

4. Fica CA, CastroSM, Soto SA, Flores MC, Oelker BC, Weitzel T. Neurocisticercosis - una enfermedad desatendida en Chile. Rev Chil Infect. 2012;29(1): 72-81. doi: 10.4067/S0716-10182012000100012

5. OMS. [Internet] Equinococosis 2016. [citado el 23 de agosto del 2016] Disponible en: http://www.who.int/ mediacentre/factsheets/fs377/es/

6. Uribe N, García C. Fasciolosis, zoonosis emergente y reemergente vista desde una dimensión ambiental. VITAE. 2013;56:1-10.

7. Marcos L, Terashima A, Legula G, Canales M, Espinoza J, Gotuzzo E. La infección por Fasciola hepatica en el Perú: una enfermedad emergente. Rev Gastroenterol Perú. 2007;27(4):389-96.

8. Rinaldi L, Gonzalez S, Guerrero J, Aguilera LC, Musella V, Genchi C, et al. A One-Health integrated approach to control fasciolasis in the Cajamarca valley of Peru. Geospat Health. 2012;6(3): S6773. doi: 10.4081 /gh.2012.124

9. Chang R, Pinto J, Guzmán P, Terashima I, Samalvides F. Caracterización clínica y epidemiológica de la infección por fasciola hepática entre los años 20032010 en el Hospital Nacional Cayetano Heredia, Lima, Perú. Rev. Gastroenterol. Peru. 2016;36(1):23-8.

10. León D, Cabanillas O. Factores de riesgo asociados a Fasciolosis humana en tres provincias del departamento de Cajamarca, Perú (Periodo 2010). Salud tecnol vet. 2014;2(1):7-13. doi: 10.20453/stv.v2i1.2061

11. González L, Esteban J, Bargues M, Valero $\mathrm{M}$, Ortiz $\mathrm{P}$, Náquira $\mathrm{C}$, et al. Hyperendemic human fascioliasis in Andean valleys: an altitudinal transect analysis in children of Cajamarca province, Perú. Acta Trop. 2011;120(1-2):119-29. doi: 10.1016/j.actatropica.2011.07.002

12. Mantari C, Chávez A, Suarez F, Arana C, Pinedo R, Ccenta R. Fasciolasis en niños de tres distritos del departamento de Junín, Perú. Rev Inv Vet Perú. 2012;23(4):454-61.

13. Cabada MM, Goodrich MR, Graham B, Villanueva P, López M, Arque E, et al. Fascioliasis y eosinophilia in the highlands of Cuzco, Perú and their asociation with water and socioeconomic factors. Am J Trop Med Hyg. 2014,91(5):989-93. doi: 10.4269/ajtmh.14-0169

14. Lopez M, White AC Jr, Cabada MM. Burden of Fasciola hepatica infection among children from Paucartambo in Cusco, Peru. Am J Trop Med Hyg. 2012;86(3):481-5. doi: $10.4269 /$ ajtmh.2012.11-0448

15. García HH, Gilman RH, Gonzalez AE, Verastegui M, Rodriguez S, Gavidia C, et al. Hyperendemic human and porcine Taenia solium infection in Perú. Am J Trop Med Hyg. 2003;68(3):268-75.

16. Moyano LM, Saito M, Montano SM, Gonzalvez G, Olaya S, Ayvar V, et al. Neurocysticercosis as a cause of epilepsy and seizures in two community-based studies in a cysticercosis-endemic region in Peru. PLoS Negl Trop Dis. 2014;8(2):e2692. doi: 10.1371/journal. pntd.0002692

17. Montano S, Villaran M, Ylquimiche L, Figueroa J, Rodriguez S, Bautista, et al. Neurocysticercosis: association between seizures, serology, and brain CT in rural Peru. Neurology. 2005;65(2):229-33.

18. Moro P, Budke C, Schantz P, Vasquez J, Santivañez S, Villavicencio J. Economic impact of cystic echinococcosis in Perú. PLoS Negl Trop Dis. 2011;5(5):e1179. doi: 10.1371/journal.pntd.0001179

19. Castillo L, Cuba Y, Mendoza C, Mispireta M, Parra J, Pacheco P. Quiste hidatídico cardiaco en un niño. Presentación de un caso. Rev Med Hered. 2012;23(1):36-40.

20. Náquira C. Las zoonosis parasitarias: problema de salud pública en el Perú. Rev Peru Med Exp Salud Publica. 2010;27(4):494-97

21. Hernández D, Cabiedes J. Técnicas inmunológicas que apoyan el diagnóstico de las enfermedades autoinmunes. Reumatol Clin.2010;6(3):173-7. doi: 10.1016/j.reuma.2009.10.003

22. Miranda-Ulloa E, Sandoval-Ahumada R, Ayala E, Vásquez-Ampuero J. Evaluación de las pruebas dot blot y aglutinación de latéx para el diagnóstico de cisticercosis en Perú. Rev Peru Med Exp Salud Publica.2014;31(2):297-301.

23. Ayala-Sulca E, Miranda-Ulloa E. Evaluación deelectroinmunotransferencia utilizando antígeno mix nativo purificado de líquido de cisticerco de Taenia solium para el diagnóstico de cisticercosis humana. Rev Peru Med Exp Salud Publica.2015;32(3):485-91.

24. Miranda-Ulloa E, Ayala-Sulca E, FloresReátegui H. Evaluación del Western blot con cinco antígenos hidatídicos para el diagnostic de equinonocosis humana. Rev peru Med Exp Salud Publica. 2013;30(2):355-67. 
25. Escalante H, Davelois $\mathrm{K}$, Ortíz P, Rodriguez $H$, Díaz J, Jara C. Estandarización de la técnica de Western blot para el diagnóstico de la fasciolosis humana utilizando antígenos de excreción-secreción de Fasciola hepática. Rev Peru Med Exp Salud Publica. 2011;28(3):454-61. doi: 10.1590/ S1726-46342011000300008

26. Zebardast N, Yeganeh F, Gharavi MJ, Abadi A, Seyyed Tabaei SJ, Haghighi A. Simultaneous detection and differentiation of Entamoeba histolytica, E. dispar, E. moshkovskii, Giardia lamblia and Cryptosporidium spp. in human fecal samples using multiplex PCR and qPCRMCA. Acta Trop. 2016;162:233-8. doi: 10.1016/j.actatropica.2016.07.004

27. Rubio JM, Tammam MA, Ta-Tang TH. Uso de PCR múltiple en el diagnóstico simultáneo de parasitosis. Biomédica. 2011;31(sup.3):253-55.

28. Tamarozzi F, Covini I, Mariconti M, Narra R, Tinelli C, De Silvestri A, Manzoni F et al. Comparison of the diagnostic accuracy of three rapid tests for the serodiagnosis of hepatic cystic echinococcosis in humans. Plos Negl Trop Dis. 2016;10(2): e0004444. doi: 10.1371/journal.pntd.0004444

29. Luvira V, Trakulhun K, Mungthin M, Naaglor T, Chantawat N, Pakdee W .et al. Comparative diagnosis of strongyloidiasis in immunocompromised patients. Am J Trop Med Hyg. 2016;95(2):401-4. doi: 10.4269/ajtmh.16-0068

30. Farfán-García AE, CastellanosDomíguez YZ, Luna-Marín KP, AnguloSilva VM. Concordancia de dos pruebas serológicas para el diagnóstico de la enfermedad de Chagas. Rev Salud Publica (Bogota). 2013;15(2):208-19.

Correspondencia: Hermes Escalante Añorga

Dirección: Calle Los Pensamientos 651.

Urbanización Palmeras del Golf, Trujillo, La

Libertad.

Teléfono: (+51) 949584200

Correo electrónico: hermesmario@hotmail.com

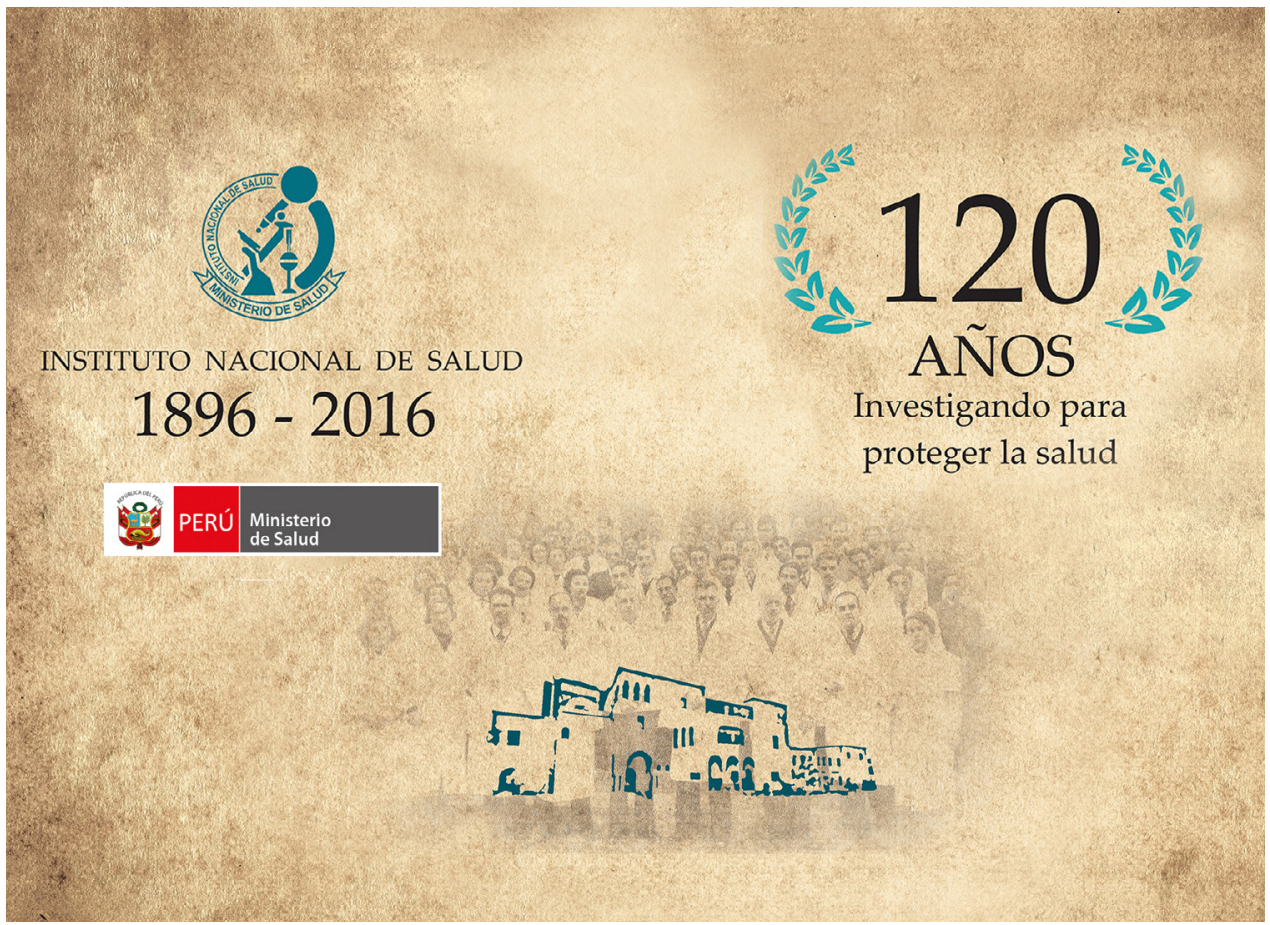

